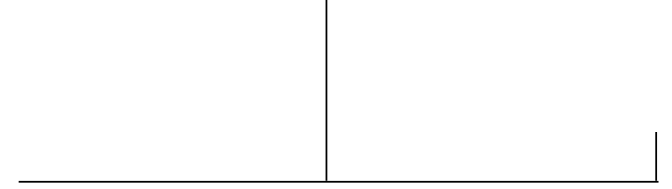

Rev. Latinoam. Psicopat. Fund., São Paulo, v. 12, n. 4, p. 743-751, dezembro 2009

\title{
Bayle e a descrição da aracnoidite crônica na paralisia geral: sobre as origens da psiquiatria biológica na França
}

Mário Eduardo Costa Pereira

A tese de medicina defendida em 1822, em Paris, por Antoine-Laurent Bayle, intitulada "Pesquisas sobre as doenças mentais”, constitui um momento de virada na história das concepções biológicas em psicopatologia. Apoiado sobre um método anátomo-clínico rigoroso, Bayle apresenta seis observações clínicas de pacientes com uma história crônica e progressiva de comportamento exaltado, ideias de grandeza, de poder e de ambição que se transformam ao final de algum tempo em delírios maníacos com agitação psicomotora. Simultaneamente, vai-se instalando um quadro de paralisia progressiva de vários grupos musculares, chegando até à incapacidade física extrema. Na fase terminal, os pacientes apresentam uma condição tipicamente demencial e de profundo comprometimento corporal, que os conduz à morte. Ao exame cadavérico, Bayle constatou a presença sistemática de uma inflamação crônica das meninges cerebrais (aracnoidite crônica) à qual ele atribui o fundamento biológico dos sintomas observados. Dessa forma, Bayle realiza uma descrição clínica rigorosa de uma entidade psicopatológica típica, de evolução crônica e progressiva e demonstra sua relação com uma lesão cerebral específica e objetivamente demonstrável. Tal descoberta, inicialmente recebida com muitas reservas, constituiria posteriormente uma espécie de paradigma para a pesquisa e para o projeto teórico e terapêutico para a psiquiatria biológica que começava a se organizar na França ao longo do século XIX.

Palavras-chave: Paralisia geral, psiquiatria biológica, Bayle, aracnoidite crônica 
No mesmo ano em que o príncipe regente Dom Pedro de Bragança e Bourbon proclamava a Independência do Brasil, na França, o jovem médico Antoine-Laurent Bayle apresentava um trabalho que se tornaria um divisor de águas na história da psicopatologia. Em 1822, esse aluno de Royer-Collard defende em Paris sua tese de medicina intitulada "Recherches sur les maladies mentales", na qual não apenas descreve de forma rigorosa as manifestações clínicas da paralisia geral, como também demonstra a relação específica desse quadro psicopatológico com a inflamação crônica de uma das membranas cerebrais, a aracnoide. Pela primeira vez na história da psiquiatria demonstravam-se os substratos anátomo-patológicos de manifestações psicopatológicas típicas, evolutivas e universalmente observáveis. A tradição pineliana, que tendia a conceber a alienação mental como expressão de desregramentos morais, entrava em crise. Abriam-se as portas para as pretensões da medicina quanto à legitimidade de sua abordagem biológica no campo dos transtornos mentais.

Bayle nasceu em 13 de janeiro de 1799, na localidade de Vernet, no sudeste da França. Muito jovem instala-se em Paris para iniciar seus estudos médicos, sendo que aos 18 anos de idade já ocupa um posto de interno em Charenton, no serviço de Royer-Collard. Ele tem apenas 23 anos quando apresenta à Faculdade de Medicina de Paris sua famosa tese. O objetivo de seu trabalho é ambicioso: trata-se de abordar, a partir de bases empíricas e anátomo-clínicas, o espinhoso tema da "natureza íntima" da alienação mental. Bayle reconhece que esse problema, dada sua extrema complexidade, foi metodologicamente 
deixado de lado mesmo pelas maiores autoridades no campo psiquiátrico de seu tempo. Ele tinha em mente, em toda evidência, a tradição descritiva e os pontos de vista quasi-psychological (Berrios, 1996, p. 175) de Pinel e Esquirol. Retomando a distinção estabelecida por Georget entre as alienações "essenciais" (decorrentes de "uma afecção idiopática, cuja natureza é desconhecida") e as alienações "sintomáticas" (decorrentes de alterações verificáveis dos órgãos corporais), Bayle se propõe a "provar com a ajuda de certo número de fatos, (...) que [além de sintomática] a alienação mental pode ser simpática", ou seja, um "distúrbio dos órgãos cerebrais determinado por um distúrbio" de outros órgãos periféricos. Em outros termos, o autor busca demonstrar que pelo menos em algumas situações clínicas é possível se encontrar alterações biológicas específicas a elas correlacionadas.

Dessa forma, Bayle divide sua tese em três partes: "Na primeira, buscamos provar que a alienação mental é, às vezes, o sintoma de uma inflamação crônica do aracnoide. A segunda tenciona demonstrar que essa doença pode ser ocasionada, mantida ou modificada por uma gastrite ou gastrenterite crônica. A terceira inclui duas observações nas quais a loucura parece ter sido determinada por uma gota irregular".

O elemento verdadeiramente revolucionário de seu estudo é, sem dúvida, a primeira parte, dedicada a demonstrar uma forma sintomática específica da loucura (folie). Nela, o autor relata seis observações de pacientes apresentando um quadro típico de alienação mental caracterizado por curso insidioso, mas progressivo, iniciando por um estado de exaltação, de intensidade variável, que evolui para um quadro de delírio maníaco generalizado, rico em ideias de grandeza e de ambição, irritabilidade e agitação psicomotora. Tais sintomas se intensificam até que o doente atinja uma fase terminal, claramente demencial, com prejuízo importante do conjunto das faculdades cognitivas, debilidade física generalizada e morte. Ao lado dessas manifestações, instaura-se desde o início, e de maneira igualmente progressiva, um quadro de paralisia geral atingindo vários grupos musculares e se manifestando por diminuição da força, marcha titubeante, dificuldades para engolir e para falar, incontinência de esfíncteres e acentuada prostração física.

Ao exame anátomo-patológico do cérebro desses pacientes, Bayle demonstra a presença de uma aracnoidite crônica em todos esses casos, à qual atribui os fenômenos psicopatológicos e neurológicos neles observados. É por isso que propõe denominar tal patologia de "aracnoidite crônica com alienação mental". Dessa forma, seguindo um rigoroso método anátomo-clínico, já plenamente desenvolvido naquela época, o autor consegue oferecer uma descrição precisa de um quadro psicopatológico típico e específico, bem como demonstrar sua relação necessária com uma inflamação crônica das meninges. Estavam, assim, co- 
locados os pilares para a edificação legítima de uma abordagem estritamente médica de fenômenos psicopatológicos.

Na verdade, o quadro clínico especificado por Bayle tem uma longa e incerta história. Sabe-se que ele já havia sido esboçado em 1672 por Willis em seu trabalho Anima bruturum Amstelo dami. Quase um século mais tarde, em 1798, também na Inglaterra, John Haslam descreveria em seu estudo intitulado Observations on insanity "as pretensões ambiciosas de certos alienados que apresentavam igualmente uma paralisia difusa", sem contudo chegar a propor que esse quadro constituísse uma entidade psicopatológica autônoma (cf. Postel \& Quetel, 1983, p. 322). Na França, Esquirol já havia indicado a extrema gravidade dos frequentes casos de alienação mental que evoluíam simultaneamente com paralisia, considerando, contudo, que se tratavam de fenômenos paralelos. Para ele, a presença de paralisia indicava um prognóstico mais reservado, com evolução para a demência. Georget, discípulo de Esquirol, considerava que a demência era o destino final de todas as loucuras incuráveis e que, em quase metade dos casos, acrescentava-se a esses estados terminais uma outra moléstia: a paralisia muscular crônica parcial ou geral (cf. Santiago, 1884, p. 8).

O termo específico de "Paralisia Geral", por sua vez, só seria cunhado após a tese de Bayle, em 1824 por Delaye e retomado em 1826 por Calmeil, a título de "Paralysie Générale des aliénés", em um livro especialmente dedicado a esse tema (Calmeil, 1826). A denominação mais conhecida, de "Paralisia Geral Progressiva" (PGP), só seria proposta em 1846 por Requin (Requin, 1846, p. 133) em um debate na Société de Médécine de Paris.

Para o leitor contemporâneo, para quem a relação entre a síndrome descrita sob o termo de "Paralisia Geral" e a neurossífilis é quase óbvia, pode ser difícil apreciar com clareza o impacto das proposições de Bayle, formuladas mais de cinquenta anos antes que Fournier proclamasse, em 1878, a origem sifilítica desse quadro e quase um século antes que o bacteriologista japonês Hydeo Noguchi identificasse, em 1913, o Treponema pallidum no cérebro de pacientes mortos em função dessa patologia. Dessa forma, o trabalho de Bayle fornece a descrição clínica detalhada da expressão sintomatológica de uma aracnoidite crônica, cuja etiologia bacteriana específica não será determinada, com certeza, senão um século mais tarde.

Inicialmente, a tese de Bayle foi recebida com muitas críticas e grande ceticismo pela comunidade médica e psiquiátrica francesa, pois ela entrava em franca contradição com os pontos de vistas hegemônicos sustentados pela tradição pineliana. Na França, até essa época, segundo a tradição inaugurada por Pinel, todas as formas de loucura eram consideradas a expressão de perturbações nervosas cerebrais. As eventuais lesões encontradas nos exames cadavéricos de alie- 
nados mentais eram consideradas apenas fenômenos secundários, decorrentes da evolução crônica do transtorno mental de base. Fiel a essa perspectiva, a posição sustentada por Esquirol reconhecia a existência de certos quadros em que se encontravam associadas perturbação mental e a paralisia, mas sua concepção era nitidamente dualista, ou seja, as perturbações paralíticas constituíam apenas uma intercorrência secundária ao processo fundamental da alienação mental evoluindo para a demência. Tratavam-se, pois, de dois transtornos distintos, a paralisia podendo ou não acrescentar-se ao curso demencial de certas formas de alienação mental. Esta permanecia de etiologia fundamentalmente "moral", susceptível de apresentar complicações neurológicas ao longo de sua evolução. Bayle será o introdutor de uma concepção unista que vê na paralisia e na demência aspectos clínicos de um mesmo processo mórbido, a aracnoidite crônica, sendo que uma e outra se desenvolvem ao mesmo tempo na maior parte dos casos.

Se em um primeiro momento, Bayle sustentava um âmbito de validade bastante limitado para suas proposições, essas tomarão um caráter muito mais generalizante em 1825 com sua Nouvelle doctrine des maladies mentales. Nessa obra, o autor defende o ponto de vista segundo o qual a causalidade fundamental da loucura deve ser procurada na "flegmasia crônica primitiva das membranas do cérebro". Nota-se assim que, tal como sustenta Bercherie (1991, p. 57), "Bayle não resistiu à tentação de estender sua descoberta à maior parte das doenças mentais".

Posteriormente, em seu Tratado das doenças do cérebro, de 1826, "Bayle confirma que ele descrevera uma doença mental absolutamente específica cuja causa orgânica era certa" (cf. Postel \& Quetel, 1983, p. 327).

Tendo enfrentado uma intensa oposição às suas ideias monistas e generalizantes referentes às causas e manifestações da paralisia geral e, por extensão, da maioria das doenças mentais, Bayle termina por abandonar a psiquiatria. Entre seus adversários mais eloquentes encontravam-se Georget, Calmeil e o próprio Esquirol. Este, com a morte de Royer-Collard em novembro de 1825, passa a ocupar o posto de médico-chefe de Charenton, tornando-se, assim, patron do serviço em que trabalhava Bayle, fato que precipitou seu abandono da especialidade.

A aceitação das ideias de Bayle referentes à Paralisia Geral foi, portanto, bastante lenta, sendo necessários quase trinta anos para que esta passasse a ser considerada uma entidade clínica autônoma e específica e para que a visão unitária dessa patologia se tornasse dominante.

Os efeitos de sua descoberta, uma vez assimilados à cultura psiquiátrica, foram da maior importância. Mesmo que, conforme Berrios (1996, p. 177) exista pouca evidência de que os alienistas considerassem a paralisia geral uma "doen- 
ça-paradigma" para as demais doenças mentais, é fato que após a assimilação das ideias de Bayle observa-se um grande impulso no desenvolvimento de uma concepção neuropsiquiátrica no campo da psicopatologia. A nascente psiquiatria biológica francesa encontrará na descoberta de Bayle uma referência central e terá nas figuras de Jean-Pierre Falret e, sobretudo, de Moreau de Tours, seus primeiros grandes protagonistas.

\section{Referências}

BAYLE, A.-L. Recherches sur les maladies mentales. Thèse de médecine de Paris n. 247, 1822. Fac-símile disponível em: <http://web2.bium.univ-paris5.fr/livanc/ ?cote $=$ TPAR $1822 \times 247 \& \mathrm{p}=4 \& \mathrm{do}=$ page $>$.

BERCHERIE, P. Histoire et structure du savoir psychiatrique: les fondements de la clinique - I. Tournai: Editions Universitaires, 1991.

BerRios, G. The history of the mental symptoms. Cambridge: Cambridge University Press, 1996.

CALMEIL, L.-F. De la paralysie considerée chez les aliénés. Paris: Ed. par Ballière, 1826. Um fac-simile dessa obra pode ser consultado no site: <http://books.google.com.br/ books?id=8GyBxEWJz64C\&pg=PA7\&dq=Paralysie+G\%c3\%A9n\%C3\%A9rale\&source= bl\&ots=fQ08AF33SK\&sig=pFrl0WVuJeeiK_Ke4flVxV8TjzM\&hl=pt-BR\&ei=ZdPuSsrKB cPblAfL1MH_BA\&sa=X\&oi=book_result\&ct=result\&resnum=4\&ved=0CBkQ6AEwAw\#v= onepage \&q=Paralysie $\% 20 \mathrm{G} \% \mathrm{C} 3 \% \mathrm{~A} 9 \mathrm{n} \% \mathrm{C} 3 \%$ A9rale \&f=false>.

Garrabé, J. Histoire de la schizophénie. Paris: Seghers, 1992.

Pessotti, I. A loucura e as épocas. Rio de Janeiro: Editora 34, 1994.

Postel, J. \& Quetel, C. (Org.). Nouvelle histoire de la psychiatrie. Toulouse: Privat, 1983.

Postel, J. La genèse de la psychiatrie. Plessis-Robinson: Institut Synthélabo, 1998. (Les empêcheurs de penser em rond).

Requin. Discussion sur la paralysie générale des aliénés: Société de Médécine de Paris, séance du 20 février, 1846. Annales Médico-Psychologiques, tome 8, p. 132-134.

SAntiago, R. F. Da natureza da paralysia geral. Tese apresentada à Faculdade de Medicina do Rio de Janeiro, em 30 de setembro de 1884. Um fac-simile dessa tese pode ser consultado em: <http://www.siaapm.cultura.mg.gov.br/acervo/teses/ TM-0198.pdf >.

SHORTER, E. A history of psychiatry: from the era of the asylum to the age of Prozac. New York: John Wiley \& Sons, Inc., 1997. 


\section{Resumo}

(Bayle y la descripción de la aracnoiditis crónica en la parálisis general: sobre los orígenes de la psiquiatría biológica en Francia)

La tesis de medicina defendida en 1822 en Paris, por Antoine-Laurent Bayle, titulada "Investigación sobre las enfermedades mentales", constituye un momento de viraje en la historia de las concepciones biológicas en psicopatología. Apoyado sobre un método anatómico-clínico riguroso, Bayle presenta seis observaciones clínicas de pacientes con una historia crónica y progresiva de comportamiento exaltado, ideias de grandeza, de poder y de ambición que se transformaron al final de algún tempo en delirios maníacos con agitación psicomotora. Simultáneamente, se va instalando un cuadro de parálisis progresiva de varios grupos musculares, llegando hasta la incapacidad física extrema. En la fase terminal, los pacientes presentan una condición típicamente demencial e de profundo comprometimiento corporal, que los conduce a la muerte. Al examen cadavérico, Bayle constato la presencia sistemática de una inflamación crónica de las meninges cerebrales (aracnoiditis crónica) a la cual él atribuyó el fundamento biológico de los síntomas observados. De esta forma, Bayle realiza una descripción clínica rigurosa de una entidad psicopatológica típica, de evolución crónica y progresiva y demuestra su relación con una lesión cerebral específica y objetivamente demostrable. Tal descubierta, inicialmente recibida con muchas reservas, constituiría posteriormente una especie de paradigma para la investigación y para el proyecto teórico e terapéutico para la psiquiatría biológica que comenzaba a organizarse en Francia a lo largo del siglo XIX.

Palabras clave: Parálisis general, psiquiatría biológica, Bayle, aracnoiditis crónica

(Bayle et la description de l'aracnites chronique dans la paralysie générale: sur les origines de la psychiatrie biologique en France)

La thèse de médecine soutenue en 1822 à Paris par Antoine-Laurent Bayle, intitulée "Recherches sur les maladies mentales" constitue un tournant dans l'histoire des conceptions biologiques en psychopathologie. Fondé sur une méthode anatomoclinique rigoureuse, Bayle y présente six observations cliniques de patients ayant une histoire chronique et progressive de comportement exalté, idées de grandeur, de puissance et d'ambition qui se transforment au bout d'un certain temps en délires maniaques accompagnés d'agitation psychomotrice. Simultanément, un tableau de paralysie progressive de plusieurs groupes musculaires se met en place, allant jusqu'à l'incapacité physique extrême. Dans la phase terminale, les patients présentent une condition typiquement démentielle et de profond affaiblissement corporel, finissant par en mourir. À l'examen cadavérique, Bayle a constaté la présence systématique d'une inflammation chronique des méninges cérébrales (arachnites chronique) à laquelle il attribue le fondement biologique des symptômes observés. Bayle nous fournit ainsi une 
description clinique rigoureuse d'une entité psychopathologique typique à l'évolution chronique et progressive et démontre son rapport à une lésion cérébrale spécifique et objectivement démonstrable. Telle découverte, reçue avec beaucoup de réserves au départ, constituera ensuite une sorte de paradigme pour la recherche et pour le projet théorique et thérapeutique de la psychiatrie biologique qui commençait à s'organiser en France au cours du XIX siècle.

Mots clés: Paralysie générale, psychiatrie biologique, Bayle, Arachnites chronique

(Bayle and the description of chronic arachnoiditis in general paralysis: on the origins of biological psychiatry in France)

Antoine Laurent Bayle's medical thesis, entitled "Studies on mental diseases" and defended in Paris in 1822, represented an important advance in the history of biological conceptions in psychopathology. Based on a rigorous anatomic and clinical method, Bayle presented clinical observations on six patients with chronic and progressive histories of exalted behavior and ideas of grandeur, power and ambition, a condition that eventually evolved to maniac delusions with psychomotor agitation. Simultaneously, a situation of progressive paralysis of several muscle groups set in, leading to extreme physical incapacity. In the final stage the patients showed a typically demential condition with serious physical impairment which led to death. Post-mortem examinations showed the presence, in all cases, of chronic inflammation of the cerebral meninges (chronic arachnoiditis), which Bayle held to be the biological basis of the symptoms noted. Bayle thus provided a rigorous clinical description of a typical psychopathological entity with chronic and progressive evolution, and showed its relationship to specific and objectively demonstrable cerebral damage. This discovery, first received with considerable reservation, later served as a type of paradigm for research and for the theoretical and therapeutic project for biological psychiatry that began in France during the 19th century.

Key words: General paralysis, biological psychiatry, Bayle, chronic arachnoiditis

Citação/Citation: PereIRA, M.E.C. Bayle e a descrição da aracnoidite crônica na paralisia geral: sobre as origens da psiquiatria biológica na França. Revista Latinoamericana de Psicopatologia Fundamental, São Paulo, v. 12, n. 4, p. 743-751, dez. 2009.

Editor do artigo/Editor: Prof. Dr. Mário Eduardo Costa Pereira.

Recebido/Received: 30.10.2009 / 10.30.2009 Aceito/Accepted: 9.11.2009 / 11.9.2009 
Copyright: @ 2009 Associação Universitária de Pesquisa em Psicopatologia Fundamental/ University Association for Research in Fundamental Psychopathology. Este é um artigo de livre acesso, que permite uso irrestrito, distribuição e reprodução em qualquer meio, desde que $\mathrm{o}$ autor e a fonte sejam citados/This is an open-access article, which permits unrestricted use, distribution, and reproduction in any medium, provided the original author and source are credited.

Financiamento/Funding: $\mathrm{O}$ autor declara não ter sido financiado ou apoiado/The author has no support or funding to report.

Conflito de interesses: $\mathrm{O}$ autor declara que não há conflito de interesses/The author declares that has no conflict of interest.

\section{Mário Eduardo Costa Pereira}

Psiquiatra, psicanalista; professor titular de Psicopatologia Clínica do Laboratoire de Psychopathologie Clinique et Psychanalyse da Universidade de Provence/Aix-Marseille (Marseille, França); doutor em Psicopatologia Fundamental e Psicanálise pela Universidade Paris 7 (Paris, França); diretor do Laboratório de Psicopatologia Fundamental da Unicamp; professor do Departamento de Psicanálise do Instituto Sedes Sapientiae de São Paulo (Brasil); membro da Associação Universitária de Pesquisa em Psicopatologia Fundamental (São Paulo, SP, Brasil); autor dos livros Pânico e desamparo (São Paulo: Escuta, 1999) e Psicopatologia dos ataques de pânico (São Paulo: Escuta, 2003).

Laboratoire de Psychanalyse et Pscyhopathologie Clinique

Université de Provence

Centre Saint-Charles

Case 37

3, place Victor Hugo

13331 Marseille cedex 3 France 